\title{
Quality Assessment for Corporate Governance Compliance: the Case of BSE- MTF Listed Entities
}

\author{
Ioan Ovidiu SPĂTĂCEAN ${ }^{1 *}$ \\ Tatiana DĂNESCU ${ }^{1}$ \\ Maria-Alexandra POPA ${ }^{1}$
}

\begin{abstract}
${ }^{1}$ Faculty of Economics and Law, EDI Department - Economic Sciences, University of Medicine, Pharmacy, Sciences and Technology "George Emil Palade” from Targu Mures, Gh. Marinescu Street, no. 38, Targu Mures, 540139, Romania
\end{abstract}

\begin{abstract}
Over the past two years a significant number of issuers have emerged on the AeRO Multilateral Trading Facility (MTF) organized and managed by the Bucharest Stock Exchange (BSE). Preliminary assessments concluded that investors' interest for the recent AeRO public offerings of equity and debt seemed to be even greater than in case of the regulated market, possibly explained by a higher return on investments. On the other hand, a preference for the AeRO market instead of the regulated market has been also noticed among the inssuers trying to avoid compliance costs related to financial reporting and corporate governance. These assumptions are relevant to sustain a research direction related to a quality assessment of compliance with relevant corporate governance principles that AeRO issuers must also embrace and implement. The research methodology includes governance compliance inspections, issuers' website screenings and annual report reviews. The sample of issuers is formed by the 20 issuers included in the BETAeRO Index launched on 11th of October, 2021. We expect that our findings will provide a relevant basis of conclusions to support a broaden utility of the Vektor transparency index, which should be extended for AeRO issuers as well.
\end{abstract}

Keywords: corporate governance, compliance statement, investors' protection, multilateral trading facility, securities' issuer

\section{JEL Classification: M42, M48}

(C) 2021 Published by ACTA MARISIENSIS, SERIA OECONOMICA, Publisher University Press Targu Mures, issued on behalf of University of Medicine, Pharmacy, Sciences and Technology "George Emil Palade" from Targu Mures, Romania

\footnotetext{
* Corresponding author: Maria-Alexandra Popa

e-mail: maria.popa@umfst.ro
} 


\section{INTRODUCTION}

Corporate governance defines a set of systems and principles to ensure that a company is managed in a manner that best meets the interests of stakeholders, promoting values such as fairness, transparency, integrity and accountability. Good corporate governance practices ensure the protection of shareholders' interests, disclosure and transparency in business transactions, compliance with the legal framework and statutory provisions, ethical business conduct and a commitment to generate value to stakeholders (Mittal S. \& Kalsie A., 2015).

In the opinion of Isaih D. and Fakoya M.B. (2017), modern principles of corporate governance justify an approach that balances the legitimate and reasonable needs, interests and expectations of stakeholders in an ethical and sustainable manner as part of the decision-making process. Other authors have argued that good corporate governance contributes to economic stability by improving the performance of companies and facilitating access to capital, having a major impact in reducing the vulnerabilities specific to financial crises (Latif B. etc., etc., 2013) or in providing security guarantees for assets or funds held by the company (Leksono A.W., Rendika V., 2018).

Some researchers (Pahuja A, \& Bhatia B.S., 2010) have analyzed the determinants of the corporate governance disclosures. Their study sought to determine the extent to which listed Indian companies disseminate information about governance practices by examining the annual reports of 50 listed companies. The study shows that there is a considerable difference in the quantitative and qualitative dimensions of the disclosures made by companies in their annual reports, leaving room for substantial improvements related to disclosure practices in this matter.

Other authors (Shahbaz T., Raja A.A.K., and Zeeshan R.A., 2012) concluded that, for investors, one of the most important aspects considered when substantiating an investment decision relates to the level of implementation of corporate governance principles, which can ensure their return on investment. In the same direction, value judgments have been made that the level of corporate governance could have an impact on the capitalization of the stock market, a dynamic indicator of measuring the size of a listed company. Thus, positive or negative information about the company causes an immediate adjustment of the trading prices, once it has been disseminated to the public. From this perspective, senior management could be motivated to improve the company's reputation on the capital market, in a linear evolution (Hasan M.S., Normah O., 2015). However, studies have also been identified that have assessed a weak link between corporate governance and the performance of companies, such as the one conducted by Kushani P. and Hirindu K. (2017) on companies listed in the Sri Lankan financial sector. Other studies (Rathnayake D.N., Sun G., 2017) expanded in Asian countries such as Singapore, Pakistan, Malaysia, including Sri Lanka have, on the contrary, highlighted a conclusion that strong corporate governance practices favorably drive the performance of a company.

As for the studies carried out on the Romanian capital market (Spătăcean O., Ghiorghiță L., 2012), they were directed mainly on the segment of the BSE regulated market, the interest on SMT AeRO being almost non-existent in previous researches. For this reason, we appreciate that our approaches to assess compliance with the relevant principles of corporate governance in the case of AeRO issuers bring added value to the global image of how persons in charge understand to adopt and implement good governance on the Bucharest Stock Exchange. 


\section{DEFINING THE RESEARCH PROBLEM}

We aim to identify possible correlations between corporate governance compliance ratios and (i) BET AeRO index weight of each issuer, and (ii) stock returns. We base our investigations on the following hypothesis:

$\mathrm{H}_{1}$ - there is a positive correlation between compliance ratios regarding the quality of corporate governance practices and BET AeRO index weight;

$\mathrm{H}_{2}$ - there is a positive correlation between corporate governance compliance ratios and the stock returns for each issuer subject to our review.

Our sample consists of 20 issuers listed on MTF AeRO within BSE, included in BET AeRO index launched on October $10^{\text {th }}, 2021$. The research methodology considered the following main activities:

- define 17 relevant corporate governance requirements according to BSE Corporate Governance Code in force for AeRO issuers starting from January $3^{\text {rd }}, 2022$;

- inspect the 2020 Annual Reports of each issuer under review, to accumulate evidence needed to support corporate governance compliance statements;

- inspect BSE trading activity reports, to observe trading prices for the relevant periods, needed to determine annual stock returns of each issuer;

- review corporate governance sections within the official websites of the issuers, in order to obtain a broader picture in terms of corporate governance compliance level.

\section{PRESENTING THE RESEARCH FINDINGS}

Based on the data obtained, we have summarized the overall compliance rates against the five relevant sections of corporate governance (Table 1). As can be seen, the sections containing general requirements and requirements for the relationship with investors, marked the highest values of the overall compliance rate. Sections containing BoD requirements, internal control and remuneration requirements recorded low overall compliance rates, suggesting significant vulnerabilities in financial reporting in terms of internal control and monitoring. We note that the overall compliance rate was determined at the level of each relevant section of corporate governance as a simple average of the individual compliance rates observed for each assertion included in that section. For example, in the case of section $0-$ General Requirements, the overall compliance rate is: $(60 \%+50 \%+60 \%+65 \%) / 4=58.75 \%$. The source of the raw data for these calculations can be found in Table 2 . 
Table 1 - Synthesized results of overall compliance ratios

\begin{tabular}{|c|l|c|}
\hline Code & \multicolumn{1}{|c|}{ Section } & $\begin{array}{c}\text { Overall } \\
\text { Compliance } \\
\text { Ratio (\%) }\end{array}$ \\
\hline O & General Requirements & $58.75 \%$ \\
\hline A & Board of Directors Requirements & $28.33 \%$ \\
\hline B & Internal Control & $22.50 \%$ \\
\hline C & Remuneration and Motivation & $35.00 \%$ \\
\hline D & Creating Value through Investor Relations & $55.71 \%$ \\
\hline \multicolumn{2}{|c|}{ Source: authors' projection } \\
\hline
\end{tabular}

Table 2 shows the CG compliance rates for each assertion that corresponds to the relevant requirements of the BSE Corporate Governance Code. These rates were computed as ratios between the number of issuers that reasonably complied with the requirements and the total number of issuers under inspection (20 issuers). Conclusions on the extent to which compliance had been reasonably achieved, were obtained through the analysis of the 2020 annual reports and the inspection of the issuers' official websites.

Table 2 - Detailed empirical results of compliance ratios for corporate governance requirements

\begin{tabular}{|c|c|c|c|}
\hline Section & $\mathbf{Q}$ & Relevant Requirement & $\begin{array}{l}\text { Compliance } \\
\text { Ratio }(\%)\end{array}$ \\
\hline \multirow[t]{4}{*}{ General Requirements } & Q1 & Distinctive CG website section, with IR function & $12 / 20=60 \%$ \\
\hline & Q2 & English version of the website & $10 / 20=50 \%$ \\
\hline & Q3 & CG Apply or Explain Statement & $12 / 20=60 \%$ \\
\hline & Q4 & $\begin{array}{l}\text { Articles of Association and BoD regulation addressing conflicts } \\
\text { of interests }\end{array}$ & $13 / 20=65 \%$ \\
\hline \multirow{3}{*}{$\begin{array}{l}\text { Section A - BoD } \\
\text { Requirements }\end{array}$} & Q5 & Disclosure of other professional commitments of BoD Members & $8 / 20=40 \%$ \\
\hline & Q6 & Disclosure of BoD Members' affiliates with a 5\% shareholder & $7 / 20=35 \%$ \\
\hline & Q7 & Annual assessment of BoD Members & $2 / 20=10 \%$ \\
\hline \multirow{2}{*}{$\begin{array}{l}\text { Section B - Internal } \\
\text { Control }\end{array}$} & Q8 & BoD approval of trades with affiliates above $5 \%$ of net assets & $4 / 20=20 \%$ \\
\hline & Q9 & $\begin{array}{l}\text { Internal audit function reporting to BoD and Superior } \\
\text { Management }\end{array}$ & $5 / 20=25 \%$ \\
\hline $\begin{array}{l}\text { Section } \mathrm{C}-\text { Remuneration } \\
\text { and Motivation }\end{array}$ & Q10 & Remuneration policy disclosures for BoD Members and CEO & $7 / 20=35 \%$ \\
\hline \multirow{7}{*}{$\begin{array}{c}\text { Section D - Creating } \\
\text { Value through Investor } \\
\text { Relations }\end{array}$} & Q11 & BoD Members and CEO CVs & $7 / 20=35 \%$ \\
\hline & Q12 & Current and Periodic Reports & $19 / 20=95 \%$ \\
\hline & Q13 & GSM relevant information & $16 / 20=80 \%$ \\
\hline & Q14 & Disclosures related to corporate events & $9 / 20=45 \%$ \\
\hline & Q15 & Dividend policy disclosures & $11 / 20=55 \%$ \\
\hline & Q16 & Forecast policy disclosures & $9 / 20=45 \%$ \\
\hline & Q17 & Annual conference meeting with analysts & $7 / 20=35 \%$ \\
\hline
\end{tabular}

Source: authors' projection 
In relation to publicly available records and accumulated evidence, the vulnerabilities considered to be significant to compliance with the relevant governance requirements concerned: (i) the annual evaluation of the BoD members under the responsibility of the President; (ii) approval by the BoD of transactions with related parties in the amount of more than $5 \%$ of the net assets; (iii) the effectiveness of the internal audit function; (iv) disclosure of affiliation relationships between BoD members and shareholders with more than 5\% of the capital and (v) the publication of the remuneration policy, including the inclusion of relevant information regarding the remuneration of $\mathrm{BoD}$ members and senior management.

Table 3 - Issuers' distribution on CG compliance intervals

\begin{tabular}{|c|c|c|c|c|}
\hline $\begin{array}{c}\text { Compliance Rate/ } \\
\text { Indicator }\end{array}$ & $\begin{array}{c}\text { Low Compliance } \\
(\text { rate < 40\%) }\end{array}$ & $\begin{array}{c}\text { Medium } \\
\text { compliance } \\
(\mathbf{4 0 \%}<\text { rate < 70\%) }\end{array}$ & $\begin{array}{c}\text { High } \\
\text { compliance } \\
\text { (rate > 70\%) }\end{array}$ & Total \\
\hline Number of issuers & 8 & 8 & 4 & 20 \\
\hline Weight (\%) & $40 \%$ & $40 \%$ & $20 \%$ & $100 \%$ \\
\hline
\end{tabular}

Source: authors' projection

Ranges for high, medium and low compliance levels have been defined against the compliance rate values. Based on the classification of the analyzed issuers (Table 3), it was determined that only $20 \%$ of issuers recorded a high level of compliance (over $70 \%$ ).

Testing the degree of correlation between the CG compliance rates and the weighting in the BET AeRO index, respectively the annual stock return generated results that were summarized in Table 4.

These results confirm divergent correspondences that could put the validation of research hypotheses into question. Thus, only two issuers out of the four with a high degree of compliance hold a percentage in the stock index of over $5 \%$ while the other two issuers hold a percentage lower than $2.5 \%$. Overall, the cumulative share in the BET AeRO index for issuers with a high degree of compliance is about $24 \%$. On the other hand, the cumulative share for the eight issuers with a low degree of compliance is over $42 \%$.

After the performance of correlation tests between the CG compliance rates and the annual stock return, the conclusions also support a divergent development. Thus, out of the total 11 issuers that recorded downsides of more than $10 \%$ in the trading price, seven issuers recorded medium and high levels of compliance rates. Moreover, of the three issuers that recorded price declines of more than $80 \%$, two issuers had a medium level of compliance and the third issuer had a high level of compliance. On the same dissenting note, the largest increases in trading prices $(+850 \%$ and $+180 \%$ respectively) were noticed for issuers with a low CG compliance rate. 
Table 4 - Empirical results of compliance ratio correlations

\begin{tabular}{|c|c|c|c|c|c|}
\hline Issuer & Industry & $\begin{array}{c}\text { Compliance } \\
\text { Ratio (\%) }\end{array}$ & $\begin{array}{c}\text { Index } \\
\text { weight } \\
(\%)\end{array}$ & $\begin{array}{l}2021 \text { Stock } \\
\text { Return (\%) }\end{array}$ & $\begin{array}{c}\text { IPO Stock } \\
\text { Return } \\
(\%)\end{array}$ \\
\hline $\begin{array}{l}\text { CHIMCOMPLEX BORZESTI } \\
\text { SA }\end{array}$ & Manufacturing & $31 \%$ & $25.54 \%$ & $850.00 \%$ & $\mathrm{n} / \mathrm{a}$ \\
\hline Holde Agri Invest S.A. & Agriculture & $75 \%$ & $12.98 \%$ & $19.85 \%$ & $\mathrm{n} / \mathrm{a}$ \\
\hline NOROFERT S.A. & Agriculture & $94 \%$ & $7.26 \%$ & $(43.88 \%)$ & $\mathrm{n} / \mathrm{a}$ \\
\hline SAFETECH INNOVATIONS & Information Technology & $56 \%$ & $6.94 \%$ & $(55.33 \%)$ & $\mathrm{n} / \mathrm{a}$ \\
\hline $\begin{array}{l}\text { ELECTROPRECIZIA SA } \\
\text { Sacele }\end{array}$ & Retail Sales & $56 \%$ & $5.72 \%$ & $32.77 \%$ & $\mathrm{n} / \mathrm{a}$ \\
\hline IHUNT TECHNOLOGY S.A. & Retail Sales & $63 \%$ & $5.36 \%$ & $(70.19 \%)$ & $\mathrm{n} / \mathrm{a}$ \\
\hline SIMTEL TEAM & Industrial Machinery & $50 \%$ & $4.84 \%$ & $4.41 \%$ & $83.08 \%$ \\
\hline AGROSERV MARIUTA & Mixed Farming & $38 \%$ & $4.73 \%$ & $9.65 \%$ & $26.67 \%$ \\
\hline $\begin{array}{l}\text { AGROLAND BUSINESS } \\
\text { SYSTEM }\end{array}$ & Agriculture & $69 \%$ & $4.42 \%$ & $(83.96 \%)$ & $\mathrm{n} / \mathrm{a}$ \\
\hline ARCTIC STREAM & Information Technology & $19 \%$ & $4.22 \%$ & $(27.68 \%)$ & $34.40 \%$ \\
\hline VISUAL FAN & Retail Sales & $38 \%$ & $3.88 \%$ & $(6.30 \%)$ & $(3.57 \%)$ \\
\hline MACOFIL SA TG. JIU & Manufacturing & $50 \%$ & $3.47 \%$ & $26.36 \%$ & $\mathrm{n} / \mathrm{a}$ \\
\hline 2PERFORMANT NETWORK & Information Technology & $88 \%$ & $2.30 \%$ & $(80.36 \%)$ & $\mathrm{n} / \mathrm{a}$ \\
\hline MAMBRICOLAJ S.A. & Retail Sales & $56 \%$ & $2.05 \%$ & $(80.92 \%)$ & $\mathrm{n} / \mathrm{a}$ \\
\hline LCS IMOBILIAR SA & Real estate & $0 \%$ & $1.79 \%$ & $180.00 \%$ & $\mathrm{n} / \mathrm{a}$ \\
\hline LIFE IS HARD S.A. & Information Technology & $100 \%$ & $1.59 \%$ & $9.76 \%$ & $\mathrm{n} / \mathrm{a}$ \\
\hline $\begin{array}{l}\text { AGROLAND } \\
\text { AGRIBUSINESS }\end{array}$ & Agriculture & $25 \%$ & $0.91 \%$ & $(12.50 \%)$ & $24.44 \%$ \\
\hline VIFRANA & Growing grapes & $13 \%$ & $0.83 \%$ & $(40.00 \%)$ & $\mathrm{n} / \mathrm{a}$ \\
\hline FIREBYTE GAMES & Video Gaming & $56 \%$ & $0.76 \%$ & $(63.12 \%)$ & $151.79 \%$ \\
\hline AIR CLAIM & Air transportation & $13 \%$ & $0.39 \%$ & $(73.99 \%)$ & $99.68 \%$ \\
\hline
\end{tabular}

Source: authors' projection

\section{CONCLUSIONS}

Our research efforts were limited in achieving the proposed objectives, at least as a result of the following: (i) a number of 4 issuers out of the 20 analyzed did not publish annual reports for 2020, as they have been admitted to trading in 2021; and (ii) a number of 7 issuers out of the 20 analyzed argued that the existence of a Board of Directors is not justified, contrary to the provisions of the Companies' Law no. 31/1990 and the Issuers' Law no. 24/2017. We therefore note that in the case of entities that have a legal obligation to audit the annual financial statements, the existence of a Board of Directors and the delegation of Company's management are legal provisions imposed by the Companies' Law. The legal obligation to audit the financial statements is induced by the Issuers' Law no. 24/2017 which provides that the annual report also contains the report of the statutory auditor.

As regards the validation of the research hypotheses formulated, we present below our conclusions. The $\mathrm{H} 1$ hypothesis, which took into account the positive correlation between the GC compliance rate and the weight in the BET AeRO stock index, was accepted to a moderate extent, given that a number of 6 issuers with a degree of compliance above $60 \%$ make up only 
$34 \%$ of the total stock index. We note in this context that the issuer Chimcomplex SA Borzești, which holds the largest share in the index (over 25\%) confirmed a low level of compliance (31\%), while the issuer Life is Hard SA, although it recorded the maximum level of CG compliance, has an insignificant weight in the AeRO stock index (1.59\%). The H2 hypothesis that positively correlated the CG compliance rate and the annual return of the stock was also accepted to a moderate extent. In support of this conclusion, we show that a number of 4 issuers with compliance rates of over $60 \%$ lost almost $70 \%$ of the trading price during 2021 . Moreover, the issuer LCS Imobiliar SA for which we were unable to determine a compliance rate, in the absence of an official website and the annual report 2020, recorded a return on the share of $180 \%$. On the basis of these justifications, we consider that the two research hypotheses were rejected, which equals to a low or non-existent level of correlation between the CG compliance rates and the weight in the BET AeRO index or the annual stock return.

As the overall level of compliance is a medium one, there is a reasonable question to what extent the issuers selected to compose the BET AeRO index are representative of the AeRO trading segment. Such a concern may also be justified from the perspective of the Vektor transparency index extension to this trading market, with a corresponding adjustment to the calculation methodology.

The future research directions are aimed at expanding the sample with all issuers on MTF AeRO, that have been admitted to trading in the last two years, including those that have not been included in the BET AeRO index. The correlation with the financial performance or the extension of the CG qualitative compliance assessment conclusions by using questionnaire-based investigative techniques may also be considered.

\section{Bibliography:}

Mittal, S., Kalsie, A. (2015, July), A Review on Corporate Governance in India: Impact on Firm Performance, International Journal of Business and Administration Research Review, Vol. 1, Issue 11, p. 170-174, ISSN -2348-0653;

Isaih, D., Fakoya, M.B. (2017, June), Effect of Corporate Governance Structure on the Financial Performance of Johannesburg Stock Exchange (JSE) - Listed Mining Firms, Sustainability, doi:10.3390/su9060867;

Latif, B. et al., (2013), Impact of Corporate Governance on Firm Performance: Evidence from Sugar Mills of Pakistan, European Journal of Business and Management, ISSN 2222-1905, Vol. 5, No. 1, p. 51-59;

Leksono, A.W., Rendika V. (2018, September) The Effect of Good Corporate Governance Mechanism and Financial Performance on Firm Value of Banking Sector Listed on Indonesia Stock Exchange (BEI) Period of 2012 - 2016, International Journal of Innovative Science and Research Technology, ISSN 2456-2165, Vol. 3, Issue 9, p. 535 - 540;

Pahuja, A., Bhatia, B.S. (2010, July), Determinants of Corporate Governance Disclosures: Evidence from Companies in Northern India, IUP Journal of Corporate Governance, Vol. IX, No. 3, p. 71;

Shahbaz, T., Raja, A.A.K., Zeeshan, R.A. (2018, July), An Investigation of Corporate Governance and Firm Performance after Revised Code 2012 in Pakistan, International Journal of Management Sciences and Business Research, Vol - 7, Issue \&, ISSN 2226-8235; 
Hasan, M.S., Normah O., (2015). The Impact of Firm's Level Corporation on Market Capitalization, Journal of Investment and Management, doi: 10.11648/j.jim.20150404.14, ISSN 2328-7713, p. 119-131;

Kushani, P., Hirindu K., (2017, March), The Relationship between Corporate Governance and Firm Performance, Management and Administrative Sciences Review, Vol. 6, Issue 2, ISSN 2310-872X, p. 73-84;

Rathnayake, D.N., Sun, G., (2017) Corporate Ownership, Governance and Performance: Evidence from Asian Countries, Research Journal of Finance and Accounting, Vol.8, No. 15, ISSN 2222-1697, p. 28-36;

Spătăcean, O., Ghiorghiță L., (2012) Testing Compliance with Corporate Governance Principles on the Romanian Capital Market, Studia Universitatis Petru Maior Journal, Series Oeconomica, Fasciculus 1, ISSN 1843-1127, p. 70-87. 